\title{
A Proposed Rule - Roadmap for the Adoption of International Financial Reporting Standards (IFRS) in Nigeria: A Research Based Perspective on FGN, NASB \& SEC
}

\author{
Augustine Ayuba \\ Lecturer Department of Accounting, Faculty of Social \& Management Sciences, Kaduna State University, P.M.B. 2339 Kaduna, Nigeria \\ ayubaaugustine@yahoo.com
}

\begin{abstract}
The Nigerian Accounting Standards Board (NASB) issued a timeline and a roadmap for the proper adoption of International Financial Reporting Standards (IFRS) by companies operating in the country. We really shed more light and detail assertions on the key issues raised by the government proposal, we proposed that the need for a globalised accounting standards or " externality" is highly overstated. A globalised and widely accepted accounting regulator is unlikely to help achieve the stated goals of comparability and consistency of financial reporting bearing in mind the nature and economic situation of the country. We posit that, Nigerian companies should be given the opportunity to choose the use of either Nigerian GAAP or IFRS rather than imposing one global monopoly set of standards that is designed to suit the need of developed countries. We concluded that, focus on auditing and investigation is very important which deserve the attention of all and sundry especially from the standards setting bodies if the aim of financial reporting will be realized in the future, for the absolute gains or benefits associated from the adoption of IFRS, which is a principle - based accounting standards are likely to be achieved only if auditors are principle - based in nature. We therefore recommend that, the federal government through the NASB or the SEC to re - consider the implications of its proposal to work hand in hand with the Federal ministry of education and the Nigerian professional bodies, such as Institute of Chartered Accountants of Nigeria, Nigerian College of Accountancy, Institute of Chartered Taxation of Nigeria etc, so that more attention will be accorded to educational judgments.
\end{abstract}

Keywords International Financial Reporting Standards(IFRS), Federal government of Nigeria(FGN), Nigerian Generally Accepted Accounting Principle(NG -GAAP), Nigerian Accounting Standards Board(NASB),Security \& Exchange Commission (SEC)

\section{Introduction}

As of 1st January 2012 all listed companies in Nigeria had to adopt IAS/IFRS in order to prepare their financial statements. This decision was issued by the Nigerian government through the minister of trade and investment dated 28th July,2008.It was aimed at enhancing the competitiveness of the Nigerian capital markets by a way of establishing a single set of globalised and homogeneous," investor friendly, oriented" and internationally recognized accounting standards. The decision to adopt IAS/IFRS in a wide and important economic area such as Nigeria cannot be over - emphasis, but in doing that the government need to

* Corresponding author:

ayubaaugustine@yahoo.com (Augustine Ayuba)

Published online at http://journal.sapub.org/economics

Copyright (C 2012 Scientific \& Academic Publishing. All Rights Reserved consider several factors that may affect the adoption of IFRS in developing countries (Zeghal \& Mhedbi, 2006), which of course Nigeria is part and parcel, despite the fact that research stream concerning international accounting standards had gained international relevance in most of the developed nations of the world. Nevertheless, IFRS adoption in Nigeria will offer a unique opportunity for researchers to explore possible ways of assessing the level of compliance and implementation of the subject matter. The first objective of the literature on international accounting standards/ International financial reporting standards is to provide an in-depth analysis on why there is need for a dual or option to choose either the NGAAP or IFRS in order to dampen the effects of the new IFRS adoption, rather than mandating a single global set of financial accounting standards as issued out by the proposed roadmap.

\section{Overview}


Is there any need for a single global set of financial accounting standards for Nigeria? A single global set of financial reporting standards is not optimal. Robust competition between standards setters is more desirable. In the context of the proposed roadmap, allowing listed companies in Nigeria to choose between using NGAAP and IFRS has a higher likelihood of generating high quality financial reporting. Also the attention should be devoted to auditing because accounting standards setters have recently undervalued the importance of verifiability as a qualitative characteristics in setting accounting standards. Reconciliatio $\mathrm{n}$ should be between the accounting and auditing standards is necessary in order to ensure proper implementation of both NG-GAAP and IFRS. In the aspect of governance and funding mechanism of standards - setting boards are very vital for creating independence as well as responsiveness to the needs of preparers and users of accounting reports. The current governance and funding policies of NASB really instill confidence unlike that of IFRS which need to be reconstituted because it lack confidence in the independence or responsiveness of the IASB. The last but not the least, the roadmap and the cost benefit analysis fails to take cogent actions on the educational sector, even in the time past ,NASB has failed in its duty to strictly monitor the inculcating of the NG-GAAP into the curricular of learning in the country.

\section{The Report on the Roadmap to the Adoption of IFRS in Nigeria}

The adoption of IFRS is more than just an accounting exercise. This is because accounting and reporting represents approximately a quarter of conversion efforts. Other areas include system changes for capturing and reporting data, re appraising the tax cycle (planning, provision, compliance and controversy),aligning of internal and external reporting and ensuring changes in internal audit plans. It is also important to note that the impact of IFRS accounting policies decisions of a parent on the subsidiary, data capture for accounting and management reporting, availability of technical resources, acquisitions and dispositions, executive compensation calculations and the basis of incentive pay, debt covenants and potential impact of IFRS - reported results, etc were considered before arriving at the roadmap. It is hereby recommended that IFRS be adopted in Nigeria. The Roadmap for the adoption the adoption is outline thus;

\section{Statement of adoption.}

It is believed that it will be in best interest of the nation to adopt IFRS. A phased transition over a period of Three years is recommended. This is anchored on the understanding that the nation will follow the milestones and timelines as enunciated above and explained hereunder. It is pertinent to state here that the transition within this earliest possible period of effective and meaningful adoption may be derailed if any of the milestones and timelines is ignored. The phases are as follows:
Phase 1: Publicly Listed Entities and Significant Public Interest Entities.

This means government business entities, all entities that have their equities or debt instruments listed and traded in the public markets (a domestic or foreign Stock Exchange or an over-the- counter markets). Examples of entities meeting these criteria include: Nigerian National Petroleum Corporation (NNPC), banks and insurance companies.

Transition date for SPEs begins 2010, with a reporting date of 2012. Transition begins by raising awareness to educate both the users and preparers of IFRS financial statements, followed by planning, training and analyzing the impact of IFRS adoption on people, systems and processes and on business of firms. By the year 2011, SPEs will then identify the key reporting data and prepare IFRS opening Statement of Financial Position (SFP).By the year 2012 SPEs are required prepares quarterly report using IFRS rules, follow audit procedures and investor relations to educate analysts, investors and manage external stakeholders. By the year 2013, SPEs would identify the loopholes in the existing system and processes by ensuring compliance and monitoring.

Phase 2: Other Public Interest Entities.

This refers to those entities, other than listed entities (unquoted, private companies) which are of significant public interest because of their nature of business, size, number of employees or their corporate status which requires wide range of stakeholders. Examples of entities meeting these criteria are large not-for-profit entities such as Charities and Pension funds. Transition date for PIEs begins by the year 2011 with a reporting date of 2013. By which period opening SFP and comparative figures are expected to be prepared. By 2013, PIEs are required to prepare quarterly reports using IFRS, audit procedures, and investor communications.

Phase 3: Small and Medium-sized Entities (SMEs).

Small and Medium-sized Entities (SMEs) refers to entities that may not have public accountability and their debt or equity instruments are not traded in a public market: they are not in the process of issuing such instruments for trading in a public market, they do not hold assets in fiduciary capacity for a broad group of outsiders as one of their primary businesses, the amount of their annual turnover is not more than N500 million or such amount as may be fixed by the Corporate Affairs Commission their total assets value is not more than N200 million or such amount as may be fixed by the Corporate Affairs Commission

i no Board members are foreigners

ii no members are a government or a government corporation or agency or its nominee

iii the directors among them hold not less than 51 percent of its equity share capital.

Entities that do not meet the IFRS for SME's criteria shall report using Small and Medium-sized Entities Guidelines on Accounting (SMEGA) Level 3 issued by the United Nations Conference on Trade and Development (UNCTAD). Transition date for SMEs begins by 2012 with a reporting 
date of 2014. SMEs commence transition to IFRS by 2012, preparing opening SFP and comparative figures and investor communications by 2013 , adopting IFRS reporting standards, and ensuring compliance and monitoring by 2014 .

\section{Nigerian GAAP Versus IFRS}

International financial reporting standards were adopted in 2005 in many countries and the world. The IASB issued several news, revised and amended standards and the (IFRIC) issued a number of new interpretations. In Nigeria companies have been complying with standards issued by the NASB for a number of years. These standards represents NG-GAAP ("Nigerian GAAP"). The NASB announced its roadmap to convergence with IFRS in September,2010. Based on this roadmap Nigerian listed companies \& significant Public Interest Entities (PIES) will be required to comply with IFRS for periods ending after 1st January,2012. Other PIES will be required to comply for periods ending after 1st January,2013, and small and medium sized entities will need to comply for periods ending after 1st January,2014.Therefore entities will need to understand the similarities and differences between IFRS and NG-GAAP. The development of IFRS is ongoing and it is therefore need to take into account changes that occur subsequent to the time when this publication was prepared. This study has been prepared by the group of PWC consultants who work extensively with both financial reporting framework. This study will be beneficial not only to companies changing over to IFRS, but also to the users of financial statement prepared in this manner.

\section{Analysis and Discussions}

Is there any need for a single globalised set of financial accounting standards in Nigeria? In fact this debate will go on and on because of the burning issue that is related to the adoption of IFRS by developing countries. A single set of high - quality global accounting standards is really an important mechanism for achieving the desired global comparability and consistency of reported accounting numbers. The issue on comparability and consistency raises two important question which of course investors, stakeholders and Nigerian government need to know: Is comparability and consistency the right goals $\&$ objective to lay emphasis on? If really they are the right goals for a developing country like Nigeria, will adoption of one global set of accounting standards help us as a country to achieve the comparability and consistency desired in financial accounting reports? Our view posit that, comparability and consistency should not be the cardinal point of financial reporting, rather financial reporting should be seen as a medium to strive for accounting standards that will help to convey a true image of the economic reality of an entity. On the other hand, academic research indicates that using a single set of uniform accounting standards will not lead to the production of comparable \& consistent financial reports that are desirable to regulators (Ball et al.2000,2003). The promise that IFRS will deliver comparability and consistency in accounting reports in Nigeria is a mere puff bearing the political, religious, cultural and economic nature of the country.

According to Jamal \& Sunder ( 2008), standards are regarded to serving two potential functions; Serving as a minimum quality standard or, Serving a coordination function. According to a survey by Collins et al. (2002), users of financial report perceive a standard to be of especially high quality from an international perspective when the standards is consistent with an underlying conceptual framework, and the financial report is perceived to reflect economic reality. On the other hand a standard setter with no competition may attempt to maximize its influence by imposing more and more standards, as predicted by the interest group theory of regulation. As a result, the extent of regulation may go beyond its socially optimal level, as such competition among the standards setters would help to control this tendency since firms that did not like one set of standards could simply adopt the other, thereby causing the "overzealous" standard setter to lose customers. However this process need not degenerate into a race to the bottom since firms could signal their commitment to quality reporting by means of the set of standards they adopt. For such a signal to be credible, some means of enforcing proper application of the firms chosen set of standards is needed. Such enforcement could be provided by either the SEC, NASB, or the FGN with sufficient powers and, hopefully, by an ethical professional accounting body in Nigeria, for the question of competition between standard setters is very complex, these argument suggests that there is a trade-off between the benefits and costs of convergence to a single set of high quality standards. The best point on this trade-off is not necessary at full standards convergence to IFRS in Nigeria by companies as outlined by the roadmap, but the issue depends on a country's social, legal, and institutional environment, and the difficulties this environment will creates in applying the converge standards. For the growing rate of corruption in Nigeria will not allow most of the companies to derive the benefits of adopting the mandatory standards set for them, there is need to allow the companies to choose either the NG -GAAP or the IFRS, rather than imposing set of a monopolistic and externality to them, since the IFRS is a principle based standards which allows for different interpretations by different countries at the end a country like Nigeria will never achieve the set aim of adopting the IFRS in years to come.

\section{Demerits of IFRS in Developing Countries}

The objective of international accounting according to 
(IASC,1990 as cited in Chamisa,E.2000 ) is that, "Globalization of capital markets appear to be the driving force behind the proposed changes and while for this reason they may well suit the purposes of the first world nations, their effect on third world countries could be catastrophic"

In lieu of the above, developing countries adopt the IFRS with the primary aim of satisfying their accounting and financial reporting requirements but not purposely helping in the harmonizing of accounting standards. These developing countries of which Nigeria is not an exception therefore select the standards that would help their course and modify those that would not be extremely beneficial to them. Developing countries pursue international harmonization of these accounting standards as far it does not hamper on the local accounting needs, laws and regulations. If the main objective for proposing the IFRS is to achieve a globalized capital market whiles most developing countries possess weaker or no capital, then surely adopting these standards can be disastrous to some degree.

In addition, Rahaman et al. (2004). is of the view that, "International Financial Reporting Standards are "carbon copies" of standards originating from the UK and the USA with strong orientations towards maximizing shareholders wealth rather than the social functions of accounting". Most emerging and third world countries have weak or even no structures to develop good accounting system and for that reason the first point of call when it comes to accounting issues is crafting and developing meaningful accounting system rather than adopting already structured standards from the developed countries. More so, the fact that these standards were developed with the economy of these developed countries as a yardstick makes the importance of the adoption of IFRS a daunting task. Mir \& Rahaman. (2004) argue that accounting should not be treated as the object of providing useful information to investors only, but a craft that serves the purpose of divergent interested groups. Since most developing countries would be pursuing different socio-economic development policies, the usefulness of standards developed with significant influence from the advanced industrialized nations remains contestable. The bearing of IFRS on the economic growth of developing countries which have adopted them is conflicting bearing in mind the past empirical studies conducted. Woolley (1998) who studied the bearing, the adoption of IAS has on the economic growth of some Asian countries and came to the conclusion that the average economic growth rate of developing countries when grouped by their approach to adoption or non-adoption of IASs was not significantly different which underscores the point that the adopters were not better off nor worse off as compared to the non-adopters. However, a similar study conducted in Africa observed a higher level of economic growth for countries that adopted with some form of modification of some of the standards to suit the local environmental factors (Larson, 1993).As such Nigeria will stand the chance of facing these difficulty in its quest of adopting a single globalised accounting standards.

\section{Conclusions}

We favor giving the Nigerian listed companies the choice of using NG-GAAP or IFRS in their financial reports and do hope that other jurisdictions in developing nations would exploit the advantages of giving choice to their own companies. By doing this, it will lead to a proper and smooth adoption of IFRS in Nigeria. We are of the same view with the gradual adoption process as stated by the proposed roadmap which will give the stakeholders and other financial market participants the ample opportunity to align their processes with IFRS, or consciously choose to maintain the NG-GAAP reporting in their financial statements. We strongly recommend that the NASB should consider the educational impact of its proposed roadmap. We are skeptical about creating a monopoly global accounting standard setter and are not convinced that benefits will accrue from the current desire for the harmonization of accounting standards. We recommend that, competition between the NG-GAAP and IFRS be given priority as a mechanism to improve the quality of financial reporting in Nigeria.

\section{ACKNOWLEDGEMENTS}

Sap productions wishes to acknowledge all the contributors for developing and maintaining this template.

\section{REFERENCES}

[1] Ball,R.,Kothari,S.P., \& Robin,A. (2000). The effects of international institutional factors on properties of accounting earnings. Journal of Accounting and Economics,36,235 - 270.

[2] Ball,R.,Robin,A., \& Wu, J.S. (2003).Incentives versus standards: Properties of accounting income in four East Asian countries. Journal of Accounting and Economics,29, 1 - 51.

[3] Committee on Roadmap. (2010). Report on the Adoption of International Financial Reporting Standards (IFRS) in Nigeria.

[4] Chamisa,E (2000). The Relevance and Observance of the IASC Standards in Developing Countries and the Particular Case of Zimbabwe. The international Journal of Accounting,35,267 -286.

[5] Choi, D., and Meek, K. (2007). International Accounting . Prentice Hall 2007.

[6] Collins et al (2002). Characteristics influencing perceptions of accounting pronouncement quality. Accounting horizons 16(2), 137 - 151 .

[7] Economic Development in Nigeria, ICAN 39 Annual Accountants Conference.

[8] Jamal,K.,M.Maier,\&S,Sunder.(2003).Privacy in e commerce: Development of reporting standards, disclosure and assurance services in an unregulated market. Journal of accounting 
research ,41,285-309.

[9] Jamal,K.,Bloomfield,R.,Christensen,T.,Colson,R.,Moehrle,S .,Ohlson,J.,Penman,S.,Stober,T.,Sunder,S.,\&Watts,R..(2010). A research - Based perspective on the SEC's Proposed Rule Roadmap for the Potential Use of Financial Statements Prepared in Accordance with International Financial Reporting Standards (IFRS) by U.S. Issuers. Accounting Horizons ,24(1),139 - 147.

[10] Mir, Rahaman, (2004) The adoption of international accounting standards in Bangladesh - An exploration of rationale and process. Emerald, 2004.

[11] Oyedele, T. (2011). An Overview of IFRS and Challenges Posed to Professionals. A paper presented at a seminar on IFRS Adoption in Nigeria. The Chartered Institute of Taxation of Nigeria.

[12] Pricewater House Coppers (2004). First-time Adoption of International Financial Reporting Standards. Pricewater
House Coppers 2004.

[13] Scott,W.R.,. Financial Accounting Theory,6th ed., Pearson Prentice Hall International Inc., Toronto.(2009).

[14] Sunder, S (2002). Regulatory competition among accounting standards within and across international boundaries. Journal of accounting and public policy 21 (autumn): 219 - 234

[15] Wooley,R.(1998). International accounting standards and economic growth, an empirical investigation of their relationship in Asia. Working paper series. Australia: School of accounting and Law, RMIT.

[16] Zeghal, D., \& Mhedhbi, K (2006).An analysis of the factors affecting the adoption of international accounting standards by developing countries. The international journal of accounting,41,373 - 386 . 